\title{
Socio-Demographic Determinants Of Fertility Behaviour Of Women: Evidence From A Panel Study Of Four South Asian Countries
}

\author{
Fauzia Maqsood \\ Faculty of Social Sciences \\ University of Gujrat \\ Ummel Baneen \\ Department of Population Sciences \\ University of Gujrat
}

\begin{abstract}
This paper aimed at estimating the socio-demographic determinants of fertility behaviour among women by using panel data of four developing countries of Asia (Bangladesh, India, Pakistan and Nepal) for the years 1994-2013. All these countries are currently on third stage of demographic transition. The researcher used age at first marriage of female (AFMF), Contraceptive Prevalence rate (CPR), Educational Attainment of Female (EAF) and Infant Mortality Rate (IMR) as proxy measures of Socio-demographic factors that determine the fertility behaviour of women in South Asian countries. On the first step the researcher used descriptive statistics to know the average and variance values in data. On the second step Panel Least Square (OLS) method was used to estimate the relationship between the variables. Results of present study revealed that age at first marriage of female, contraceptive prevalence rate and educational attainment of female were negatively associated with total fertility rate, while, Infant mortality rate was positively related with total fertility rate. It was concluded that efforts could be placed on these socio-demographic variables to control or to regulate fertility behaviour of women.
\end{abstract}

Keywords: Social, Demographic, Determinants, Fertility, Behaviour, Transition

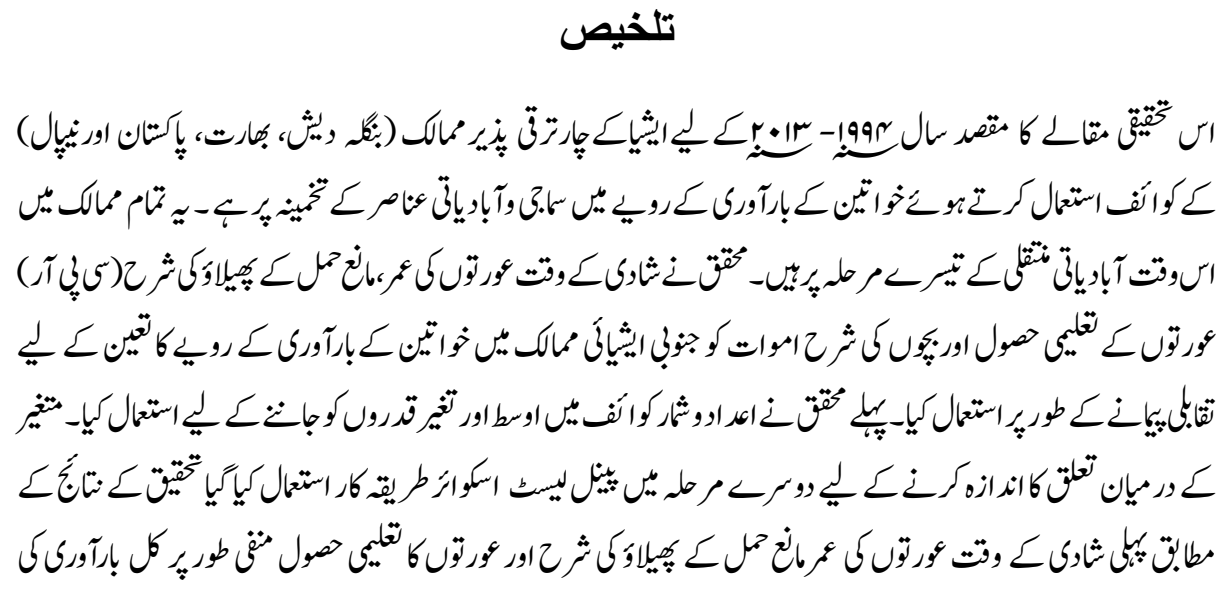




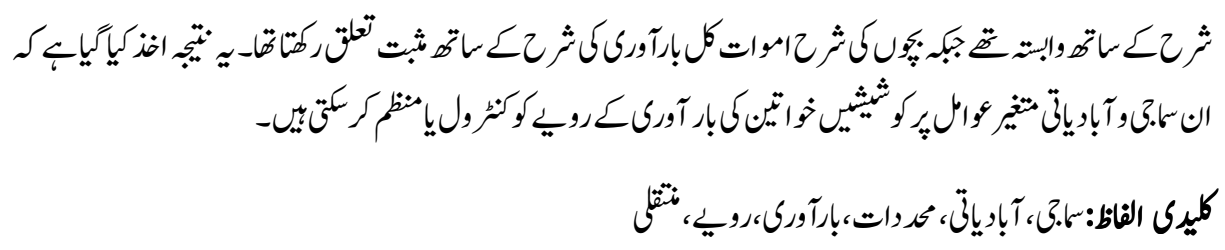

\section{Introduction}

The world is undergoing a sharp demographic change. All the countries of the world are facing changes in their demographic characteristics. It has been argued that demographic characteristics of Asian region particularly the Southeast and South Asia are quite unique and this region is also comprised of thirty percent of the total world population. This region has showed trends of high fertility infant mortality rates over the past few decades that are now declining. However, the demographic trends of the south Asian countries depicted that the fertility rate was 4.29 births per woman in 2003 which declined by 1 birth per woman in 2008. Furthermore, the child mortality rate also decreased from 102.5 per thousand births to 81.63 births from 2003 to 2008 respectively (Teguh, 2009).

Many socio-demographic factors are causing the demographic transition. Parent's educational level, female labour force participation, age at marriage, infant mortality and life expectancy at birth are some of the major factors behind demographic transition. In Bangladesh (the South Asian Country) particular factors such as the knowledge of family planning, economic cost of raising children, female education and employment are identified as important determinants of fertility rate (Hossain and Tisdell, 2003).

Education is considered as a direct and potential indicator of the status of a population and has a contributing effect which causes variations in the level of fertility. Increasing level of education decreases the reproductive span by raising the age at marriage, raising the tendency to be in labor force, encouraging a favorable attitude towards small family size norm and improving the awareness and use of family planning methods (Patnaik 1985; Arora 1990; Vashisht et al. 1991).Education is taken as one of the important and highly significant factor in reproductive behaviour (Josipovic, 2007). Singh et al. (2002) also established the fact that education affects reproductive behaviour of women up to a significant extent. Education has become one of the most important modern social factor that influences fertility. Female education is more inversely related to fertility as compared to education of male. It is seen that better educated women have more favorable attitude towards fertility control as they are more likely to seek professional advice and use a contraceptive technique (Brolchain, 1988). It has also been observed that spread of education among women is a key factor that contributes to the higher level of awareness of health problems and their utilization (Panikar, 1979; Nag, 1984). 
Many studies have examined that age at marriage is negatively associated with the total fertility rate. The higher age at marriage leaves women with reduced reproductive span condenses that eventually results in low fertility rate (Choudhary, 1984;Jolly, 1981; Kaur, 2000). It has been also estimated that if age at marriage increases from the age of 16 to 21 , the number of births would be decreased by $20-30 \%$ (Cochrane and Zachariah, 1983).

Developing countries show trends of high fertility and high infant and child mortality rates. Whereas developed nations show opposite of it that is low women are more likely to have low level of fertility with low level of infant and child mortality. Thompson (1929) and Notestein (1945) discussed various reasons as to how infant mortality affects fertility. High infant mortality leaves parents with uncertainty and they want to ensure living children by having more number of children. At the same time, high fertility tends to raise infant mortality, because of biological and behavioural reasons. Similarly, increasing female labour force participation rate may lead to and is the result of lower fertility (Toor, 2007).

The present study is aimed at investigating the socio-demographic determinants of fertility behaviour among women by comparing the statistics of four South Asian countries; that are at stage three of demographic transition.

\section{Objectives}

- To examine the relationship between educational attainment of females and fertility behaviour

- To find out the relationship between age at first marriage of females and fertility behaviour

- To find out the relationship between infant mortality rate and fertility behaviour

- To investigate the relationship between contraceptive use and fertility behaviour of female

\section{Literature Review}

Adhikari (2010) by using a sample of 8644 ever married women of reproductive ages analysed various demographic, socio-economic and cultural factors to investigate differentials of fertility in Nepal. Birth rate had decreased in Nepal since 1981. He found that the number of children ever born (CEB) were double for the illiterate women as compared to the literate one. Further, CEB decreased by a statistically significant value ($0.15)$ because of the delay in age at first marriage of the women. Number of children ever born to Muslim women were more as compared to the Hindu women if both had never been exposed to mass media. Income is another important determinant of CEB as number of children ever born to poorest women were more as compared to the richest women. The number of women who experienced child deaths was having double number of children ever born as compared to those women who had not experienced the child 
mortality. Furthermore, CEB is higher among those women who had less knowledge of family planning methods than women who had knowledge of family planning methods. However, the women who used family planning methods earlier had more CEB than females who never used.

Panopoulou and Tsakloglou (1999) found that fertility is inversely associated with level of education of women, urbanization and family planning methods but positively associated with the level of infant mortality. However, there was no significant relationship between fertility level and females' labour force participation.

Al Qudsi (1998) collected data from Arab countries and investigated that fertility is a function of real GDP per capita, urbanization rate, female education and infant mortality rate. The results of the study strongly supported the hypothesis that cross-country heterogeneity leads towards the differential fertility levels and the female education level leads towards lower fertility level. However, child mortality rate and son preference by the parents was positively related to the fertility level.

Ainsworth et al. (1996) analysed that data of Sub-Saharan African Countries. The study revealed that female's years of schooling was negatively correlated with the fertility level in all the countries under study. Moreover, the trends were also the same for rural and urban areas of those countries.

Hirschman and Guest (1990) conducted a survey in four Southeast Asian countries (Indonesia, Malaysia, Philippines and Thailand). They found that postponement of marriage, increased level of access to reproductive health services, low rate of infant mortality, family structure, the increase in the education level particularly for female, cultural, tradition and religious beliefs resulted into low level of fertility. These findings support demographic transition theory which includes the proposition that socioeconomic conditions change the incentives or having the children.

Yamada in 1984 investigated the relationship between the infant mortality rate and fertility rate by using the time series methodology. The results of the study depicted that infant mortality and fertility were dependent on each other. The study also revealed that infant mortality decline due to an increase in the income per capita that ultimately help to decline the fertility level.

\section{Theoretical Framework}

Various socio demographic factors have been analyzed to investigate fertility behaviour of women. The relationship between fertility and the other socio-demographic variables can be seen in the glimpse of theory. Demographic Transition theory seems to cover the 
objectives of present study that fertility behaviour may be determined by sociodemographic variables such as female age at marriage, female educational attainment, contraceptive use and infant mortality rate. Central theme of this theory is that socioeconomic modernization leads towards an initial decline in mortality, this decline reduces the large family size and eventually leads to low fertility level (Davis, 1963 and Notestein, 1953).

Notestein (1953) presented Demographic Theory that explained how the transition in social structure of society leads towards demographic transition. He explained that the transition of several broad level social and economic changes for instance the advancement of education, rational thinking, loosening of traditional forces, economic development and the emergence of new roles for women leads towards demographic transition.

The following diagram illustrates the causal link between fertility trends and sociodemographic variables ${ }^{1}$.

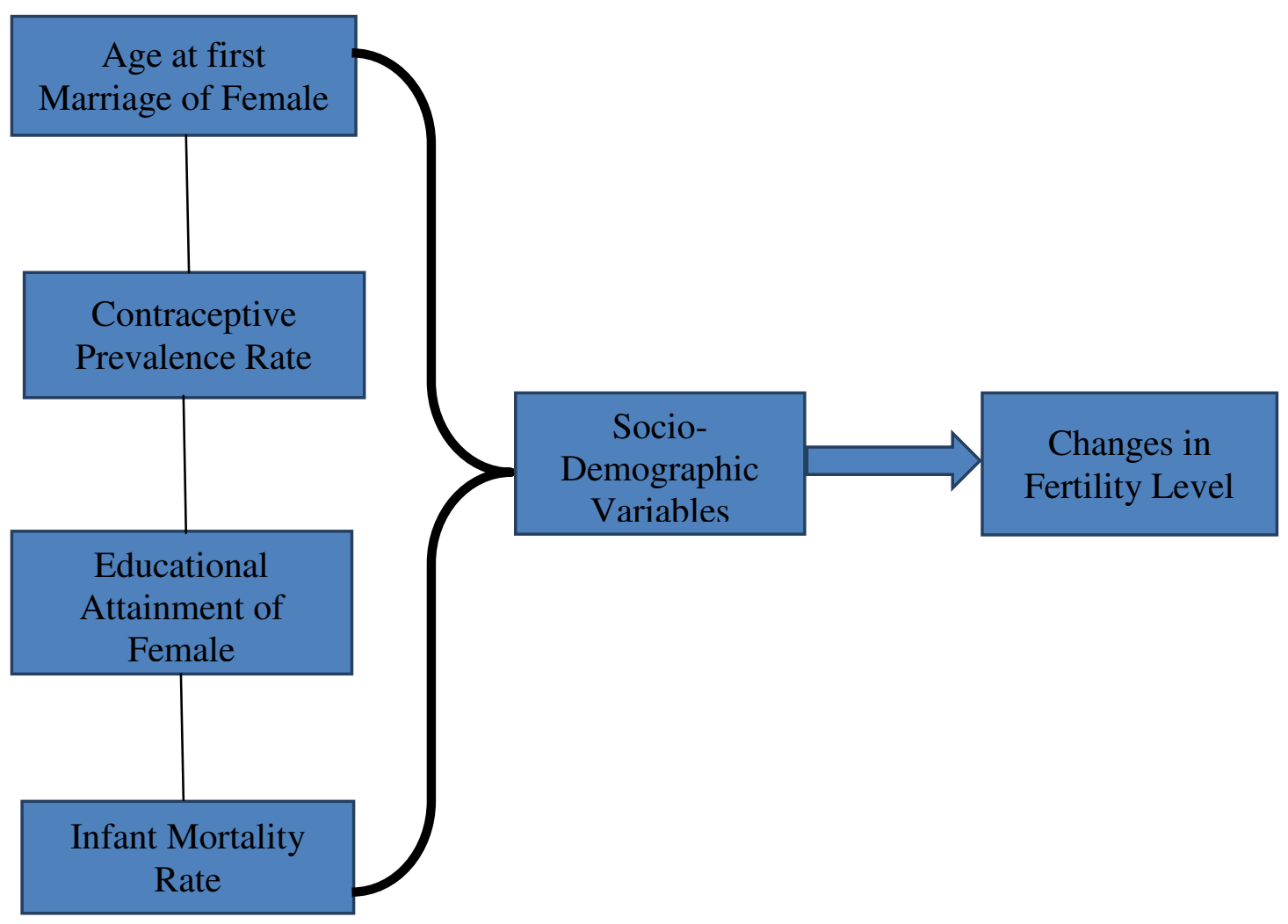

Figure 1: Causal link between Fertility trends and Socio-demographic Variables 


\section{Data and Methodology}

The present study aimed at investigating the socio-demographic determinants of fertility behaviour among women. Data was collected from United Nations World Population Prospects for four countries (Pakistan, Bangladesh, India, and Nepal) from 1994 to 2013. These are the South Asian Countries and according to literature these are at the third stage of demographic transition. These countries have declining birth rate with declined death rate. Panel study technique was used to measure the empirical analysis.

For data analysis, following model was estimated:

Fertility $($ TFR $)=\mathrm{f}(\mathrm{AFMF}, \mathrm{CPR}, \mathrm{EAF}, \mathrm{IMR})$

$\mathrm{TFR}=$ Total Fertility rate, $\mathrm{AFMF}=$ Age at First Marriage of Female, $\mathrm{CPR}=$ Contraceptive Prevalence Rate, EAF=Educational Attainment of Female, IMR=Infant Mortality Rate Crude birth rate and total fertility rate were the indicators of fertility. According to the data from United Nations World Population Prospects educational attainment, age at marriage, infant mortality, and contraceptive prevalence rate were used as proxy measures of the socio-demographic determinants of fertility behaviour among South Asian women. In present study, fertility was the dependent variable and EAF, CPR, AFMF, and IMR were the independent variables. Descriptive statistics showed the average and dispersion of the data. After the descriptive measures, regression analysis was used to measure the empirical analysis.

\section{Results and Discussion}

The primary step in analyses was to check trend of the data. For this purpose the researcher used measures of central tendency.

Table: 1

Descriptive Statistics

\begin{tabular}{|l|c|c|c|c|c|}
\hline Statistics & TFR & AFMF & EAF & CPR & IMR \\
\hline Mean & 3.375138 & 20.17438 & 2.488625 & 42.67562 & 62.80375 \\
\hline Maximum & 5.499000 & 22.81000 & 4.450000 & 61.50000 & 98.80000 \\
\hline Minimum & 2.208000 & 18.00000 & 0.850000 & 13.00000 & 33.10000 \\
\hline Std. Dev. & 0.815360 & 1.466047 & 0.890502 & 12.28351 & 17.72838 \\
\hline
\end{tabular}

Table is showing the descriptive measures of dependent variable (Total Fertility Rate) and independent variables (AFMF, EAF, CPR, IMR). On the average TFR was 3.375138 with the standard deviation 0.815360. While on the average AFMF was 20.17438 with standard deviation 1.466047. The mean value of EAF was 2.488625 with the 0.890502 standard deviation and CPR had mean value 42.67562 with standard deviation 12.28351. IMR had a mean value of 62.80375 with 17.72838 standard deviation. 
After knowing the trend of data for the four countries (Pakistan, India, Bangladesh and Nepal), the next step was to find out the relationship between dependent and independent variables whether it exists or not. Panel least square method was used to measure the relationship between the variables. The results of the estimation are shown in Table 2.

Table: 2

Co-efficient and Probability of Variables

\begin{tabular}{|l|c|c|c|c|}
\hline Variable & Coefficient & Std. Error & t-Statistic & Prob. \\
\hline AFMF & -0.109961 & 0.019254 & -5.711212 & 0.0000 \\
\hline CPR & -0.035294 & 0.003775 & -9.348604 & 0.0000 \\
\hline C & 6.417752 & 0.488433 & 13.13947 & 0.0000 \\
\hline EAF & -0.181052 & 0.037779 & -4.792342 & 0.0000 \\
\hline IMR & 0.018033 & 0.001952 & 9.239217 & 0.0000 \\
\hline
\end{tabular}

Above table shows that Coefficient of AFMF is -0.109961 which means one unit change in AFMF causes - 0.109961 change (decrease) in TFR, one unit change in CPR causes 0.035294 unit change (decrease) in TFR. Coefficients of EAF and IMR are showing that one unit change in EAF and IMR causes -0.181052 and 0.018033 unit change in TFR.

The results in Table 2 show that AFMF has significant relationship with TFR. The pvalue of AFMF (0.0000) rejects $\mathrm{H}_{0}$ at $5 \%$ level of significance which states that there is no relationship between AFMF and TFR. Consequently this model approves the $\mathrm{H}_{1}$ which states that there is relationship between AFMF and TFR. Similarly, the p-values of CPR, EAF and IMR, (0.0000) rejects the $\mathrm{H}_{0}$ which states there is no relation of TFR with CPR, EAF and IMR and accepts $\mathrm{H}_{1}$ which states that there is relationship between the variables.

Age at first marriage of female is negatively correlated with the fertility rate. The increase in age at marriage decreases the reproductive span for a female and ultimately decreases the frequency of conception. As Kaur (2000) indicated that higher age at marriage shortens the reproductive span which results in the fertility rate reduction. Consequently, a rising age at marriage helps in lowering the birth rate.

Contraceptive prevalence rate is also inversely related to the fertility rate. Use of effective birth control methods limits the births and can help to limit the number of children per women. The increase in rate of contraceptive prevalence can decrease the total fertility rate.

Educational attainment of female has a negative relationship with fertility rate. As Singh (1994) argued that sufficient literature is available on the importance of female education 
and participation in the labor market in reducing fertility rates and the general improvement in social welfare. Sackey (2005) and Vavrus and Lasern (2003) conducted the analysis on role of female's education in determining their fertility behaviour in developing and developed countries. They suggested that as investment in human capital increases and as more women participate in the labour market, the fertility behaviour of households was bound to change, in favour of fewer children. Empirical evidence from both developed and developing countries unambiguously revealed that female education was associated with a decrease in fertility.

Increase in infant mortality can lead to increase in chances of subsequent birth. Infant mortality rate has a significant relation with fertility rate. Teguh (2009) conducted a Panel study on Southeast and South Asian countries. He found that fertility rate is high among southeast and south Asian countries as compared to the other countries of the world. However, the trend is now decreasing rapidly. The study revealed that the increase in the infant mortality rate leads to increase in fertility rate. It means that this increases the inclination for demand of children. This situation leads the parents to have more number of children.

Table: 3

Tests for Goodness of Fit and Auto-correlation

\begin{tabular}{|l|c|c|c|}
\hline R-squared & 0.950779 & Mean dependent var & 3.375138 \\
\hline Adjusted R-squared & 0.948153 & S.D. dependent var & 0.815360 \\
\hline S.E. of regression & 0.185656 & Akaike info criterion & -0.469379 \\
\hline Sum squared reside & 2.585117 & Schwarz criterion & -0.320502 \\
\hline Log likelihood & 23.77515 & Hannan-Quinn criter. & -0.409690 \\
\hline F-statistic & 362.1816 & Durbin-Watson stat & 0.352107 \\
\hline Prob(F-statistic) & 0.000000 & &
\end{tabular}

The R-squared value (0.950779) is supportive to the model. The value of Durbin-Watson is 0.352107 . It does not lie between 1.5 to 2.5 . Random effect model was applied to detect autocorrelation and on the basis of this test it can be inferred that there is auto correlation problem. F-statistic value is showing the model is fit because this value is less than 0.5 .

\section{Conclusions and Policy Implications}

This study investigated the socio-demographic determinants of fertility in four South Asian countries. Here, researcher used different indicators to measure the sociodemographic variables. Data of four countries was taken from 1994 to 2013. AFMF, CPR, EAF and IMR were used as the proxy measures of socio-demographic variables. The results of the study showed that AFMF, CPR and EAF have negative relationship with 
TFR while IMR has positive relationship with TFR. Researcher firstly found the descriptive statistics to check the variation and dispersion of the data. Then estimated regression coefficients, which were used to see the relation between dependent (TFR) and independent variables (Socio-demographic determinants). Based on empirical findings, it is suggested that policy makers could focus on reducing the fertility by focusing on the socio-demographic factors of the country. Eventually the aim of reducing fertility is to decrease the population growth rate without which the economic development could not be accelerated. Especially, in the countries where the resources are already scarce, population growth and socio-economic development are closely related to each other. The policies and development plans for the socio-economic growth must be planned in innovative and realistic manner. Education plays the role of an important component in the overall development of a country. It cannot stand with the modern technological world. The education attainment of female is especially very important because it has significant effect on fertility level of the population, as the literature and findings of present study highlighted. The standard and quality of family planning services and overall health services should be improved because the family planning programmes have been failed due to the poor services in many South Asian countries. Improved family planning services lead to increase in the contraceptive prevalence rate that consequently reduces the chances of fertility. Infants must be provided with the health and conducive environment to reduce the incidences of infant mortality.

\section{References}

Adhikari, R. (2010). "Demographic, Socio-economic, and Cultural Factors Affecting Fertility Differentials in Nepal", BMC Pregnancy and Childbirth, vol.10:19, pp.111.

Ainsworth et al. (1996). The Impact of Women's Schooling on Fertility and Contraceptive Use: A Study of Fourteen Sub-Saharan African Countries", The World Bank Economic Review, vol.10, pp.85-122.

Al-Qudsi, S. (1998). "The Demand for Children in Arab Countries: Evidence from Panel and Count Data Model", Journal of Population Economic, vol.11, pp.435-452.

Arora, G. (1990). Social Structure and Fertility, New Delhi: National Book Organization.

Becker, G. S. (1992). "Fertility and the Economy" Journal of Population Economics, vol.5, pp.185-201.

Becker, G. S. (1991). A Treatise on the Family, Cambridge: Harvard University Press. 
Bloom, D. E., Canning, D., \& Sevilla, J., (2003). "The Demographic Dividend: A New Perspective on the Economic Consequences of Population Change", Population Matters, ARAND.

Bhrolchain, M.N. (1988). "The Contraceptive Confidence Idea: An Empirical Investigation". Population Studies, vol.42:2, pp.205-225.

Cochrane, Susan H., \& K. C. Zachariah (1983). Infant and Child Mortality as a Determinant of Fertility: The Policy Implications, World Bank Staff Working Papers No. 556, Washington, D.C.: World Bank.

Chaudhry, I.S., Malik, S. \& Hassan, A. (2009). "The Impact of Socioeconomic and Demographic Variables on Poverty: A Village Study" The Lahore Journal of Economics, vol.14, pp.1, 39-68.

Cincotta, R.P. \& Engelman, R. (1997). "Economics and Rapid Change: The Influence of Population Growth" Population Action International.

Davis, K. (1963). "The theory of change and response in modern demographic history" Pop Index, vol.29, pp.33-39.

Hirschman, C. \& Guest, P. (1990). "The Emerging Demographic Transitions of Southeast Asia”, Population and Development Review, vol.16:1, pp.121-152.

Hossain, M. A. \& Tisdell, C. A. (2003). "Fertility and Female Labor Force Participation in Bangladesh: Causality and Co Integration", Social Economics, Policy and Development Working Paper Number 36, School of Economics: University of Queensland.

Josipovic, D. (2007). "Education and Fertility: Do Educated Parents have Fewer Children?", Anthropological Notebooks, vol.13:2, pp.35-50.

Kaur, H. (2000). "Impact of Income and Education on Fertility" J Family Welfare, vol.46:1, pp.70-76.

Lam, D. \& Duryea, S. (1999). "Effects of Schooling on Fertility, Labour Supply and Investments in Children, with Evidence from Brazil." The Journal of Human Resources, vol.34:1, pp.160-192.

Nag, M. (1984). "Fertility Differentials in Kerala and West Bengal: Equity - Fertility Hypothesis an Explanation”, Economic and Political Weekly, vol.19, pp.33-41. 
Notestein, F. (1945). "Population - The Long View" in T. Schultz (ed.), Food for the World, Chicago, Chicago University Press, pp.36-57.

Notestein, F. (1953). "Economic Problems of Population Change', in Proceedings of the International Conference of Agricultural Economists, London, Oxford University Press, pp.13-31.

Panikar, P.G.K.(1979). "Resources not the Constraint on Health Improvement". Economic and Political Weekly, vol.19, pp.33-41.

Panopoulou, G. \& Tsakloglou, P. (1999). "Fertility and Economic Development: Theoretical Considerations and Cross-Country Evidence". Applied Economics, vol.31:11, pp.1337-1351.

Patnaik, M. M. (1985). “Fertility Behaviour” New Delhi: Janki Publications.

Schultz, T.P. (1993). "Mortality Decline in the Low-income World: Causes and Consequences" American Economic Review, vol.83, pp.337-342.

Sackey, H.A. (2005). "Female Labor force Participation in Ghana: The Effects of Education". African Economic Research Consortium Research Paper 150, Nairobi.

Singh, R.D. (1994). "Fertility-Mortality Variation Across LDCs: Women's Education, Labor Force Participation and Contraceptive Use". KYLOS. vol.47:2, pp.209-229.

Teguh, D. (2009). "The Determinants of Fertility in Southeast and South Asian Countries: an Analysis of Panel Data". Institute for Economic and Social Research (LPEM FEUI), Department of Economics, University of Indonesia. Staff paper No. 6.

Toor, I.A. (2007). "Returns to Education: The Case of Fertility" Pakistan Economic and Social Review, vol.45:1, pp.107-123.

Thompson, W. (1929). “Population” American Journal of Sociology, vol.34, pp.959-975.

UNESCAP Population Data Set, accessed in 10 April 2010.

Vavrus, F. \& Larsen, U. (2003). "Girls Education and Fertility Transition: An Analysis of Recent Trends in Tanzania and Uganda". Economic Development and Cultural Change, vol.51:4, pp.945-976. 
Vashisht, B. K. \& Rana, R. K. (1991). "Education, Fertility and Work Participation of Woman" In: VS Mahajan (ed.): Women's Contribution to India's Economic and Social Development. New Delhi: Deep and Deep, pp.345-347.

Yamada, T. (1984). "Causal Relationships between Infant Mortality and Fertility in Developed and Less Developed Countries". NBER Working Paper Series, p.1528.

Prof. Dr. Fauzia Maqsood is Dean, Faculty of Social Sciences, University of Gujrat.

Ummel Baneen is Associate Lecturer in the Department of Population Sciences, University of Gujrat. 